\title{
12. Channelling human scaled modes to build repurposed street networks
}

\author{
Kevin J. Krizek and David A. King
}

\subsection{EMERGING LANDSCAPES AND PRIORITIES IN FUTURE TRANSPORT PLANNING}

City leaders are pressed to consider how emerging transport technologies will change existing urban transport portfolios. New types of vehicles - automated cars, scooters, electric bikes - will continue to emerge in innovative new forms. Yet any new vehicles will need to integrate with existing transport modes on the streets, which are currently dominated by large cars and sport utility vehicles (SUVs). This leaves fundamental questions of how to appropriate space in streets to different forms of movement. Any transport planning decision, ideally, would ensure future conditions with high levels of accessibility (King and Krizek, 2020), while also stewarding the environment and promoting justice. This chapter posits how and why planning for bicycles and bicycle-like vehicles can be used as a guiding principle to enhance both mobility and cities' overall welfare.

We argue that many urban settlements, even most North American cities, belie their bicycling potential. They are closer to being set up for easy bicycling than most people recognize; a change that is much needed is based on designing streets differently. In this chapter we present a perspective drawing largely from North American contexts but with applicability elsewhere, to describe a rationale and strategy that underscores the merits of bicycle-like transport in future considerations and its feasibility. The last section outlines a strategy built on network development to seed changes that can spark a transport revolution in many cities across the globe.

\subsection{CURRENT CONTEXT RELATIVE TO NEW TECHNOLOGIES}

Private automobiles have historically dominated the transport landscape in cities since World War Two (WW2). Expressing concern for streets was 
synonymous with looking after the needs of cars. Planning and engineering institutions have followed suit by installing rigid design guidelines and manuals. Decades-long practices to engineer streets favouring cars is a well-documented phenomenon (Norton, 2008). Planning was boring, lacking shake-up from new innovations, and for a prolonged period (post-WWII to the turn of the 21 st century), quietly supporting cars while punishing other modes. Notwithstanding periodic flashes, largely in the 1970s with experimental forms of vehicles or a bicycle boom (Reid, 2017), not much has changed outside of the Netherlands and Denmark and a few other communities in Northern Europe. Lack of change is particularly noticeable in American cities and suburbs.

This staid context, just described, serves as a backdrop for ideas where innovative technologies are being promoted with much excitement and smaller vehicles are increasingly seen in a new light. New vehicles are cleaner and smarter. Some are backed with breakthroughs in electric battery power technologies. Other ways in which they vary from their predecessors, both cars and bikes, are in terms of size, speed or navigational requirements. Innovations might be as small as a hoverboard, or larger than the biggest car on the road. In terms of speed, they might have limited capacity, or rival the fastest of sports cars. The user may or may not be required to engage with the vehicle, for example in terms of navigation. Furthermore, some of these vehicles can provide revolutionary solutions to existing mobility problems in cities.

However, at least three issues arise from these prospects. First, transport futures based on any one of these innovations are speculative: as is the case in projecting any future, rates of adoption are built on prospect, while benefits and costs are unknown. Second, the size and shape of many of the innovative vehicles (such as versions of automated vehicles) are modelled after existing cars; more car-sized vehicles denigrate the built environment because of the space they require. Third, the manner in which new vehicles will integrate with existing fleets and the fabric of street systems is complicated to plan for (Gössling, 2020). The prospects for any vehicular invention are likely to be less revolutionary than proponents promise. We suggest that prudent transport planning practice does not hold out hope for unproven forms of technology.

These types of uncertainty permeate several dimensions of transport planning (Bertolini, 2012; Marsden and McDonald, 2019). This uncertainty should not stifle or preclude planning efforts to create transport systems different from the current ones, however. Our purview directs the conversation to designing future urban streets. Absent from most conversations about how to plan for the future of streets, we argue, are compelling ideas derived from sound planning principles, based on known technologies; actions that preserve the health of cities and are able to be acted on tomorrow. The idea draws from lessons gleaned from one of the oldest, most environmentally friendly and equitable 
modes of transport: the bicycle. It means drawing into focus an opportunity that awaits should new and safe networks for short trips be developed; networks that favour human scale modes.

\subsubsection{Bicycles are Valuable Modes to Plan For}

Bicycles represent vehicles that prize human scale dimensions while also satisfying wide-ranging mobility needs. The type of vehicle to which we refer might be a bicycle in the truest definition. Alternatively, it might represent a vehicle with 'bicycle-like' characteristics in terms of speed, size or character. It would go faster than simply walking and might top out at roughly 30 $\mathrm{km} / \mathrm{h}$. A 20 minute trip averaging $21 \mathrm{kph}$, for example, would cover a range of 7 kilometres. In terms of size, the vehicle could encroach upon but not egregiously exceed the size of existing cargo bikes. This would help to ensure increased efficiency for how valued street space is used. In terms of operation, the vehicle would demand human qualities for some power and navigation. This would help ensure some human characteristics, rather than relegating everything over to technological advances.

Beyond fundamental characteristics of the vehicle, bicycles can benefit in that they are a known product, having been around for a century. This condition has allowed an established base of knowledge to accrue about their use, one that has been quickly burgeoning in recent years (Krizek et al., 2018; Pucher and Buehler, 2017). ${ }^{1}$ Burgeoning research, for example, helps planners and researchers to understand bicycling's role in satisfying different travel markets. Matched with past knowledge, this research provides even more certainty to the already known environmental determinants that help to spur more bicycle use (Nello-Deakin, 2020). This research provides ample guidance on how to design streets and the factors that undermine cycling safety. We know the knock-on effects of having more bicycling in terms of air pollution, physical activity, liveability, and more (Götschi et al., 2016). We know what bicycles can and cannot do, particularly in Europe, where many cities have enthusiastically embraced cycling.

We do not suggest that bicycles should be the only vehicles allowed on city streets. Rather, new vehicles should be developed that increase access and mobility, so long as they mostly subscribe to the bicycle-centred characteristics mentioned above. Electric bicycles, scooters, modified golf carts and other small vehicles can all co-exist with other street users, provided the rules of the road are guided by cycling. As bicycles and bicycle-like vehicles require space on city streets to operate safely, our focus here is to expose the rationale for their value and then describe a process to steward that space. For the remainder of the chapter, in the interest of parsimony, we use 'bicycles' as a label that is inclusive of all human scale vehicles. 


\subsection{SETTLEMENT PATTERNS AND BICYLING'S POTENTIAL}

Fuelling the rationale and potential for a focus on bicycles hinges on understanding three phenomena: the patterns of settlement, bicycle trip distances and the imminence by which bicycle networks could be developed. We overview factors addressing the first two, with a focus on describing a strategy to address the third.

The distance to most destinations for which urban residents travel provides a first point of evidence. Every other time a driver in a United States (US) city gets in a car they travel less than 6.5 kilometres (Krizek and McGuckin, 2019). Simply put, urban settlements have origins and destinations that are reasonably proximate to one another. This finding applies to both cities and suburban environments, recognizing that the latter are characterized by separated land uses and auto-centric streets (Hess et al., 1999). Yet, walking trips are rarely more than $1.5 \mathrm{~km}$ (Yang and Diez-Roux, 2012), and travel less than $6.5 \mathrm{~km}$ is not so far as to require the type of motorization afforded by automobiles. Alternatively, consider an inventory of 86000 residences from Tempe, Arizona (USA), a typical suburb in a sprawling region (Capasso Da Silva et al., 2020). Close to 80 per cent of these homes have most services reachable within $6.5 \mathrm{~km}$ from home. This leaves open rich prospects to satisfy a market of urban trip-making using modes other than automobiles.

More than $1 \mathrm{~km}$ but less than $7 \mathrm{~km}$ is the range where bicycles thrive. Analysing data from bicycle use sourced from the Netherlands, China, India and the US reveals Figure 12.1. The shape of the curve is largely similar across all modes; ${ }^{2}$ what is notable is the x-axis, measuring trip distance (Arasan et al., 1994; Harms and Kansen, 2018; Iacono et al., 2008; Zhang et al., 2014). Bicycling use drops quickly with initial distance gains. But the integral of the curve between 1.5 and $6.5 \mathrm{~km}$ presents a 'sweet spot' as the majority of all cycling trips fall within this range and roughly three-quarters of all bike trips are less than 4 miles $(6.5 \mathrm{~km})$.

A major challenge in realizing more bicycling stems from the safety of conditions provided for their use. While many streets might be low-stress most of the time, characterized by having few cars or slowly moving ones, they fail to connect people to where they want to go. Otherwise, bicyclists are mostly relegated to high-stress travel environments, at least in most North American cities. The importance of streets can be further gleaned by examining how many jobs are available by bicycling in the 50 largest US cities. Using any street (low or high stress), more than 15000 jobs are available, on average, within a 20 minute bike ride. In using only low-stress streets, a cyclist can reach a third of those (Owen and Murphy, 2019). ${ }^{3}$ While these measures speak 


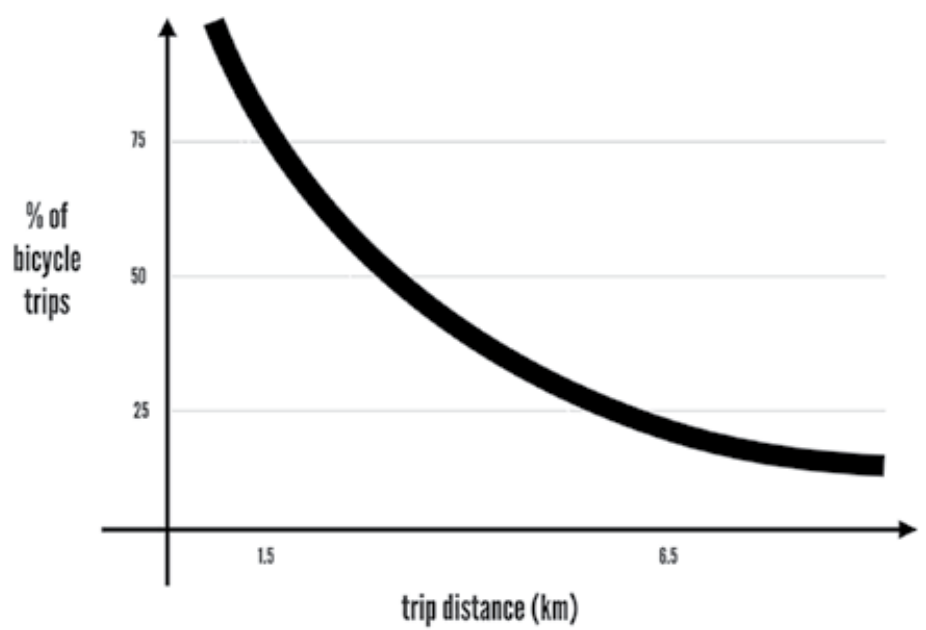

Figure 12.1 Distance decay curve for the distance of cycling trips from localities around the world

only to employment, it is not too far of a reach to apply similar logic to other purposes of travel. Most urban settlements could be set up for bicycling.

\subsubsection{Streets can Change their Use}

Streets can and do change character. The marks that automobile-based practices have etched into the canvas of streets are not indelible. The primary hurdle in realizing the above gains is to ensure safe networks for bicycling; networks which are lacking in most cities. Redesigning street networks for better transport extends to how cities could support new vehicle types, those with size and speed similarities to bicycles, which will maintain high levels of access to jobs and opportunities, but at far less cost to society.

Consider the past post-industrialization period, where streets, including many still familiar to us all, have seen walking, omnibuses, streetcars, bicycles and, ultimately, cars and trucks. Former layers are embedded and are exposed as streets are repaired and torn up: vestiges of earlier lives, tracks from streetcars, horseshoes, and even ruts from Roman chariots. Some progressions, from one dominant mode to another, occurred in only a few years. They might change character with the diurnal cycle. During a rush hour compared to the middle of the night, streets might go from full and slow to nearly empty, yet 
speedy. Or a traffic lane in a street can change based on the direction of travel. ${ }^{4}$ Streets have high potential to be swayed away from further auto-based practices. When considering potential futures that are different from what currently exists, this is helpful to keep in mind. Globally, many cities pursued strategies to change the nature of their streets - temporarily or permanently - in response to COVID-19, usually resulting in ways favouring bicycles. Many of those applications were relatively ad hoc, changing streets that were relatively easy to change. We now turn to describe a process of repurposing street space to prioritize the application of new networks.

\subsection{HOW NETWORKS GROW}

\subsubsection{Positive Externalities}

We first reflect on existing street networks and contextualize them against broader thinking. Street systems have structural properties that are embodied in all networks. They convey matter or energy from one point to another through nodes that are connected by links. These nodes and links develop based on inputs from each, and information external to the network. Natural networks such as plant leaves, for example, receive inputs from the amount of natural light or, alternatively, soil moisture. Rivers or streams may grow from conditions affecting the amount of water running off the landscape. Communication networks are based on how quickly new nodes in the network (for example, new users) acquire that mode of communication. Extending these principles to transport networks is limiting, however, because transport networks respond to political and economic triggers. Transport networks develop by responding to some forces that can be analogous to natural systems, but they are more influenced by available funding or land use planning, each of which carry highly political dimensions.

\subsubsection{Feedback Loops}

Still, there are meta-level patterns. A property that holds across the growth of transport networks is that links and nodes grow based on the positive externalities that are generated when a link or a node is improved. Any upgrade makes that part of the network more valuable to existing and potential users. Additional users of the network spur demand for more upgrades, thereby initiating a positive feedback loop. Should there be a demand to use the network concomitant with an improved link or node, the improvement spurs more demand (e.g., Levinson, 2008).

Many factors moderate the strength and speed of the feedback loop, and we turn to discussing the opportunity to stimulate that loop for bicycling. A first 
factor stems from knowing the latent demand to use the network; evidence for this was explained above (that is, the amount of trip-making in urban areas that is less than $6.5 \mathrm{~km}$ ). Next, important factors involve knowing the location and size of any improvement, together with the stage of the development of the network (that is, whether it is nascent or mature).

Most mature cities have mature street networks. In a mature automobile-oriented street system, it is more difficult to realize an individual improvement from a system-wide perspective. For example, should a problematic intersection be improved, its impact on the network overall is slight, because the improvement applies to only one of thousands of intersections in a city. For a nascent, emerging network, the reverse is true. Each improvement has a higher impact owing to its relative contribution to an improved system. For example, should there be only one bicycle lane in town and another is added, that network becomes twice as strong. To heighten the impact of a second bicycle facility, it is best to ensure that the second can play off the first. This underscores why it is important to strategically locate improvements. An example drawn from prior writings (Levinson and Krizek, 2018) helps to explain this.

Suppose a city aims to strengthen its bicycling network. It begins changing the street near an elementary school by painting it to indicate the school traffic zone. For this improvement, the primary benefactors are the children who frequent the school, as the reach beyond this population is limited (similar to having a single fax machine but no one to fax with). Should city officials improve a segment of street a few blocks away near the recreation centre, a network is born. Two links are formed - school to recreation centre ('rec'), and vice versa - benefiting two different populations. Should an improvement be realized in front of the grocer that is three blocks north, the network now serves six markets: school to rec, rec to school, grocer to rec, rec to grocer, grocer to school, and school to grocer. Each improvement on the network provides benefits to users travelling for different types of trips. Should more improvements come online, for example next to the library, the number of markets grows from six to 12 . More nodes and links with improvements bring higher value for these improvement as recognized by community members, loosely following a growth dynamic that resembles Metcalfe's law (Gilder, 1993) and broader network effects: more users of the service provides a value of the product to others, and the value of the product increases according to the number of others using it.

In a growing network, plotting the number of improvements (that is, users or market penetration) versus time typically reveals an S-shaped curve (Figure 12.2). Following a nascent period where improvements are slow to pick up (Hall, 2004), continued improvements help to trigger a rapid acceleration phase. This point, also referred to as take-off, is the location in the curve with 


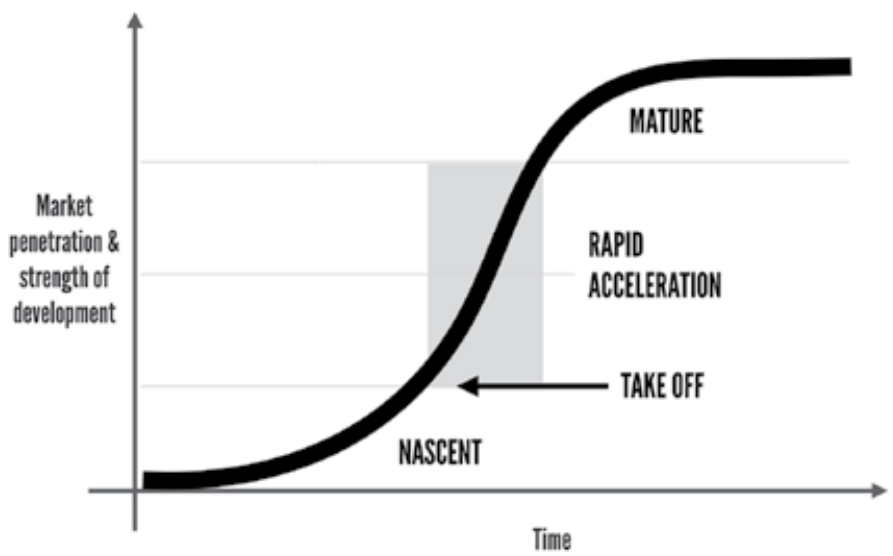

Figure 12.2 Transport networks develop based on improvements which vary by stage of development for the network, as depicted in an $S$-curve

the greatest inflection relative to the initial growth rate, and getting to this point is most important (Golder and Tellis, 1997). Growth continues until the network reaches a mature status or a saturation point. Given that cycling networks are currently nascent in most cities, this can work to bicycling's advantage in terms of quickly attracting new users (e.g., Félix et al., 2020). Efforts to grow the network can be quickly realized, thereby moving past the take-off phase. Another important factor working in bicycling's favour is that most streets are already built and paved. Legal rights of way have already been preserved; there is minimal need to find resources to lay the road surface. Streets can be inexpensively repurposed through minimal signage or re-marking efforts.

\subsubsection{Locations to Sow Seeds}

The above rationales point to the following: streets can change the types of vehicles they support, and a bicycle network can be swiftly built from existing streets. Yet, the speed at which the network develops depends on where seeds are planted. This means strategically improving links and nodes to street networks that have high potential for attracting cyclists. It is a crucial step to initiate and strengthen the point of take-off. First places to target are locations in cities where many short trips start or stop, those less than 4 miles. These locations vary by city and it is necessary to contend with long-standing equity 
concerns about which streets, in which neighbourhoods, to change (Tucker and Manaugh, 2017). Our efforts here identify and briefly describe some generalities of these places - schools and campus environments, neighbourhood retail and the first/last stage of trunk transit service - each of which serve as attractions for many short trips.

Owing to the size and characteristics of the population affected, streets near schools and campus environments provide the first areas to target. School travel is an issue that varies considerably in culture. It often starts with which type to attend (for example, public or private); other factors quickly follow suit. The public education school system in the US provides only one frame to view this issue, albeit a large one, and we rely on it here as an example. More than 50 million children in the US attend school; three-quarters of them travel less than $8 \mathrm{~km}$ to do so, thereby roughly translating to 75 million school trips, two per day, for 160 days. Recognizing that $8 \mathrm{~km}$ is a healthy distance, if one were to assume that two-thirds of those might be within comfortable cycling distance, this equates to 50 million school trips per day. Primary explanations for why children do not cycle to school start with unsupportive conditions on streets. Therefore, improvements through programmes such as Safe Routes to Schools have demonstrated progress along these lines. Making streets safer around schools has yielded an 18 per cent uptick in the number of children walking or bicycling there (McDonald and Aalborg, 2009); exactly the type of dynamics referenced here. Campus environments such as universities provide other good locations with high proportions of travellers without cars and lots of short-distance travel.

Trips near neighbourhood retail mark a second location. Within 6-7 km from most homes, urbanites and suburbanites alike have many services available. Acknowledging that nearby services are not always the ones that are frequented by residents, the geographical distribution of such establishments suggests that most are being supported by people travelling no more than a few kilometres to do so.

Bicycle-like vehicles, however, are not suited for longer-distance passenger trips in cities; such travel might be better relegated to train or bus. Locations along the trunk service, possibly terminals or other popular stops, is where many short-distance trips to final destinations begin. Passengers can disembark transit and use bicycles for the last stage (or vice versa for the first stage). This strategy increases the overall trip shed (the area that can be served) by transit, and helps further to strengthen the market for short-distance transport. Furthermore, it allows faster service along the line haul (trunk) portion because of fewer stops. One need look no further than the power of the shared bicycle system offered by Dutch rail to understand the possible impact in this respect; that system of 15000 bicycles has grown to accommodate 3 million rides per year, all of which start or stop at train stations. 


\subsubsection{Completeness}

Mounting improvements to support bicycling near the above locations is a first step. Changes to one part of the network have multiplicative effects: a fundamental principle that helps networks to grow quickly. But any network is only as strong as its weakest link. Researchers have a much-needed role here to identify locations that serve the above criteria, particularly those that connect key nodes and then link those subnetworks to form a larger one. Consider how dedicated bicycle lanes on key links of networks often vanish at intersections. Think about how each turn away from dedicated land may or may not be met with a facility that supports bicycling. Beyond individual links, bicyclists often find themselves exposed to high-stress environments at nodes. The need to cross just one troubling intersection, following the weakest link principle, has paralyzing effects for even dedicated cyclists.

\subsection{CONCLUSION}

Owing to emerging types of vehicles, city leaders will be increasingly challenged to prepare their streets to best serve future transport needs. Transit and pavements (and cafes) will continue to vie for attention. These needs will compete with other demands on streets such as storing utilities, providing conduits for emergency services, and picking up rubbish. Given that the rights of way are largely fixed - expansion, reduction or relocation is unlikely - all of this underscores the demand for finding space-efficient and low-cost options that offer high mobility. Prior eras of transport planning found many answers in prioritizing car use. But these decisions made decades ago are insufficient to solve the present generation's problems. In times of high uncertainty, planners and city leaders will need to experiment with furnishing new types of streets (Bertolini, 2020). They will benefit from a well-grounded and evidence-driven theory to test.

This chapter presents a rationale and strategy to prioritize actions that favour bicycles as a proxy for human scale vehicles. Doing so advances the public interest with the fewest negative consequences. It means not holding out hope for unproven mobility interventions, or furthering the status quo, largely featuring cars, which denigrate characteristics of human scale cities. Enabled by the framework offered here, cities can experience how small successes coalesce to create substantive gains. 


\section{NOTES}

1. Papers that address bicycling, according to the Web of Science (from 1991 to 1995 relative to 2011 to 2016), have seen a thirteenfold increase, including systematic catalogues of the emerging knowledge base (e.g., Handy et al., 2014).

2. Gathering data from these studies and plotting thresholds using the exponential function provides the aggregated function shown in Figure 12.1.

3. The average number of jobs reachable in 20 minutes via any street for the 50 largest US cities is 15191 ; using only low-stress streets, it is 5364 . The differences were less in Oklahoma City, Philadelphia, Richmond and Louisville, which revealed less than 50 per cent difference; the biggest differences were in Tampa Bay, Columbus and Las Vegas.

4. For example, reversible lanes that are used for high-occupancy tolls lanes (for example, Minneapolis) or Phoenix's 'suicide lanes' on 7th Avenue and 7th Street, which are reversible centre lanes on arterials with limited left turns.

\section{REFERENCES}

Arasan, V.T., Rengaraju, V.R., and Rao, K.K. (1994). Characteristics of trips by foot and bicycle modes in Indian city. Journal of Transportation Engineering, 120(2), 283-294.

Bertolini, L. (2012). Integrating mobility and urban development agendas: a manifesto. DisP-The Planning Review, 48(1), 16-26.

Bertolini, L. (2020). From 'streets for traffic' to 'streets for people': can street experiments transform urban mobility? Transport Reviews, 40(6), 734-753.

Capasso Da Silva, D., King, D.A., and Lemar, S. (2020). Accessibility in practice: 20-minute city as a sustainability planning goal. Sustainability, 12(1), 129.

Félix, R., Cambra, P., and Moura, F. (2020). Build it and give 'em bikes, and they will come: the effects of cycling infrastructure and bike-sharing system in Lisbon. Case Studies on Transport Policy, 8(2), 672-682.

Gilder, G. (1993). Metcalfe's Law and Legacy, republished from Forbes. https://www .discovery.org/a/41/, accessed 13 August 2020.

Golder, P.N., and Tellis, G.J. (1997). Will it ever fly? Modeling the takeoff of really new consumer durables. Marketing Science, 16(3), 256-270.

Gössling, S. (2020). Integrating e-scooters in urban transportation: problems, policies, and the prospect of system change. Transportation Research Part D: Transport and Environment, 79, 102230.

Götschi, T., Garrard, J., and Giles-Corti, B. (2016). Cycling as a part of daily life: a review of health perspectives. Transport Reviews, 36(1), 45-71.

Hall, B.H. (2004). Innovation and diffusion. National Bureau of Economic Research.

Handy, S., Van Wee, B., and Kroesen, M. (2014). Promoting cycling for transport: research needs and challenges. Transport Reviews, 34(1), 4-24.

Harms, L., and Kansen, M. (2018). Cycling facts. Netherlands Institute for Transport Policy Analysis (KiM). Den Haag: Ministry of Infrastructure and Water Management.

Hess, P.M., Vernez Moudon, A., Catherine Snyder, M., and Stanilov, K. (1999). Site design and pedestrian travel. Transportation Research Record, 1674(1), 9-19.

Iacono, M., Krizek, K., and El-Geneidy, A.M. (2008). Access to destinations: how close is close enough? Estimating accurate distance decay functions for multiple modes and different purposes. University of Minnesota and Minnesota Department 
of Transportation. Report \# 4 in the series Access to Destinations Study Report \# 2008-11.

King, D.A., and Krizek, K.J. (2020). The power of reforming streets to boost access for human-scaled vehicles. Transportation Research Part D: Transport and Environment, 83, 102336.

Krizek, K.J., and McGuckin, N. (2019). Shedding NHTS light on the use of 'little vehicles' in urban areas. Transport Findings. https://doi.org/10.32866/10777.

Krizek, K.J., Sharmeen, F., and Martens, K. (2018). JTLU special issue editorial. Journal of Transport and Land Use, 11(1), 805-810.

Levinson, D. (2008). Density and dispersion: the co-development of land use and rail in London. Journal of Economic Geography, 8, 55-77.

Levinson, D.M., and Krizek, K.J. (2018). Metropolitan Transport and Land Use: Planning for Place and Plexus. New York: Routledge.

Marsden, G., and McDonald, N.C. (2019). Institutional issues in planning for more uncertain futures. Transportation, 46, 1075-1092.

McDonald, N.C., and Aalborg, A.E. (2009). Why parents drive children to school: implications for safe routes to school programs. Journal of the American Planning Association, 75(3), 331-342.

Nello-Deakin, S. (2020). Environmental determinants of cycling: not seeing the forest for the trees? Journal of Transport Geography, 85, 102704.

Norton, P.D. (2008). Fighting Traffic: The Dawn of the Motor Age in the American City. Cambridge, MA: MIT Press.

Owen, A., and Murphy, B. (2019). Access across America. University of Minnesota, Center for Transportation Studies, Accessibility Observatory. CTS Report No. 19-19.

Pucher, J., and Buehler, R. (2017). Cycling towards a more sustainable transport future. Transport Reviews, 37(6), 689-694.

Reid, C. (2017). Bike Boom: The Unexpected Resurgence of Cycling. Washington, DC: Island Press.

Tucker, B., and K. Manaugh (2017). Bicycle equity in Brazil: access to safe cycling routes across neighborhoods in Rio de Janeiro and Curitiba. International Journal of Sustainable Transportation, 12, 29-38.

Yang, Y., and Diez-Roux, A.V. (2012). Walking distance by trip purpose and population subgroups. American Journal of Preventive Medicine, 43(1), 11-19.

Zhang, H., Shaheen, S.A., and Chen, X. (2014). Bicycle evolution in China: from the 1900 s to the present. International Journal of Sustainable Transportation, 8(5), $317-335$. 